\title{
Impact Report of Apar Foundation Limited on Educational, Health, Nutrition and Psychosocial support Activities, Kampala, Uganda
}

\author{
Sonali Sanjay Thakrar*, Cheruiyot K. Stephano**, Shruti Sureshkumar Patel**, Catherine Kamagaju** \\ DOI: 10.29322/IJSRP.11.02.2021.p11050 \\ http://dx.doi.org/10.29322/IJSRP.11.02.2021.p11050
}

\begin{abstract}
Purpose of the study is assess the accomplishment of all the expected results as outlined in the project document and detailed in the annual work plans during the entire project period/cycle as well as assesses all the different project activities carried out. Its objectives are to determine to what degree the project outcomes and outputs were achieved, to determine what category of beneficiaries and in what ways they benefitted and to look at the following dimensions of the project impact, relevance, effectiveness, sustainability and efficiency. The assessment was conducted in the communities of Kampala and Wakiso (Acholi quarters district. A combination of qualitative and quantitative techniques such as review of documents, Key Informant Interviews (KIIs), survey questionnaires, FGDs, field visits and observations were used. The main target group were mothers, single mothers, pregnant women, HIV+ women, children, adolescent girls, VHTs, stake holders. All interviewees were randomly selected from a wide range of beneficiaries and stakeholders. The findings of the study showed that Seventy-seven (77\%) percent of the respondents said that services helped them make healthier well-being choices or improved health. Eighty-seven (87\%) of the respondents felt that the learning sessions improved their child's learning needs. Ninety-two (92\%) of the respondents said that the nutrition services were helpful to them and their children. There was an increased change in children's ability to cope, emotional and social well-being as a result of psychological support provided. The study recommended that health services $32 \%$ and Livelihoods at $28 \%$ are more preferred for future programming. Formation of partnerships and groups for empowerment especially Youth and Women. There is need to source for more funding for expansion of activities to new areas and increased field visits. There is need to collaborate with local leaders and fully utilize VHTs during implementation of activities.
\end{abstract}

Index terms: Apar Foundation Limited, Impact report

\section{INTRODUCTION AND BACKGROUND}

The Apar Foundation Limited is a nonprofit organization established in 2017 by the current Chief Operating Officer, Shanta Patel Rabadiya. The sole purpose of the Foundation is to improve the lives of vulnerable children, and their families through nutrition, primary healthcare and education. Founded and guided by the principles and teachings of Lord Swaminarayan and His Divine Holiness Pramukh Swami Maharaj, Apar Foundation Limited highlights the virtues of selfless service to the society. It is through the dogma of His Divine Holiness Pramukh Swami Maharaj that Apar Foundation acquired its creed and motto "In the joy of others lies our own." The Foundation has mainly focused on the well-being of children and parents alike, who have been rendered displaced and therefore vulnerable likely due to disaster and conflict. Apar Foundation has worked in partnership with corporations such as International Medical Foundation, Kampala School of Physically Handicapped, International Family Support Centre, Ruboni Child 

ISSN 2250-3153

Care Initiative and Kids Club Kampala to deliver services to Kamuli, Kasese, Ruboni, Kakooga and Kiraro; in districts such as Kampala and Wakiso. As a result, the Apar foundation has thus far been able to impact over 21,818 beneficiaries through its services

\section{Table 1: Summary of Apar Foundation Activities}

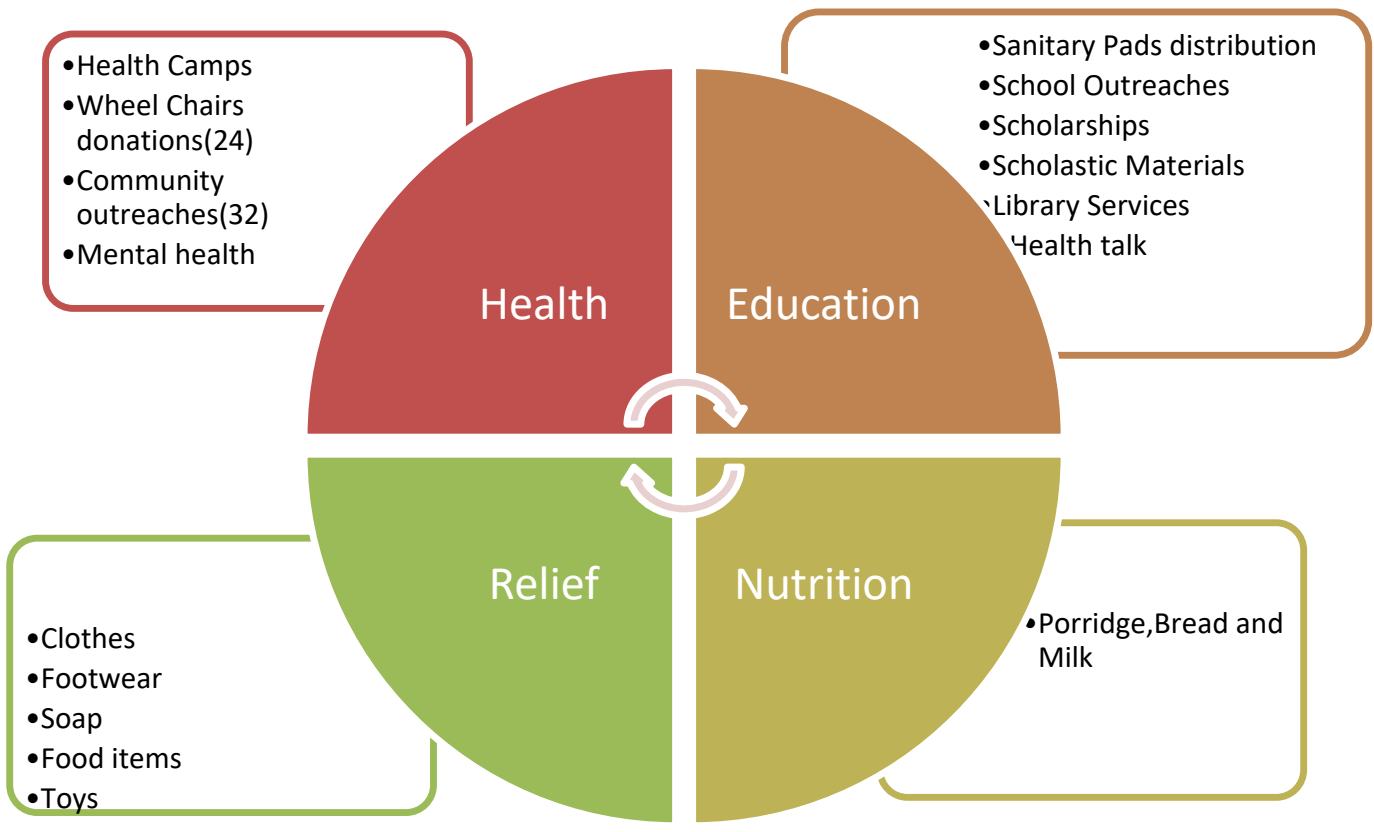

\section{Objectives of the Assessment}

- Determining to what extent, the project outcomes and outputs were achieved. The project outcomes were;

a) Improved well-being of children's health and emotional behavior

b) Enhanced household,economic and educational support

c) Improved community integration.

- Determining what category of beneficiaries and in what ways they benefitted?

- Look at the following dimensions of the project impact, relevance, effectiveness, sustainability and efficiency.

\section{Scope of the Assessment}

The approach followed the standard evaluation criteria (Relevance, Effectiveness, Efficiency, Impact and Sustainability) in answering the evaluation questions.

i. Relevance:Measured the extent to which the projectintervention objectives and design respond to beneficiaries needs.

ii. Effectiveness:Assessed and documented the extent to which project objectives were achieved.

iii. Efficiency:Assesses whether the project activities were implemented at reasonable cost, i.e. how well inputs/means are being converted into outputs, in terms of quality, quantity and time, and the quality of the results achieved.

iv.Impact:Examined to what extent has the intervention generated or is expected to generate significant positive or negative, intended or unintended, higher-level effects, for example, how the services implemented have helped the community members' physical health and economic status.

v. Sustainability:Determined whether the net benefits of the intervention are likely to continue. 


\section{METHODS AND APPROACH}

\section{Approach to the assignment}

Field data collection was conducted through random selection of respondents. A total of 90 respondents was returned out of a potential 2500 beneficiaries.

\section{Methodology}

A combination of qualitative and quantitative techniques such as review of documents, key Informant Interviews(KIIs), Survey questionnaires, Focus group discussions and field visits were used. Sampling units were the targeted beneficiaries of the project(mothers) and these were randomly sampled from the communities. The rest of the respondents were sampled purposively. Focus group discussions and individual interviews(one-to-one) were held with the beneficiaries while in-depth key informant interviews were conducted via email to selected partner staff.

\section{Data Collection}

Data collection was carried out using the Kobo collect tool and later transferred to the online kobo server for management and analysis. Focus group discussion guide by data collectors to obtain quantitative and qualitative data respectively.

\section{Sampling}

All interviewees were randomly selected from a wide range of beneficiaries. A total sample of 118 respondents was covered in this exercise as summarized below;

\section{Table 2: Breakdown of respondents by type of interview}

\begin{tabular}{llll}
\hline Type of Interview & Interviewed & Male & Female \\
\hline Survey Questionnaire & 95 & 6 & 89 \\
Key Informant Interview & 10 & 5 & 5 \\
Focus Group Discussion & 13 & 3 & 10 \\
Total & $\mathbf{1 1 8}$ & $\mathbf{1 4}$ & $\mathbf{1 0 4}$ \\
Percentage & $\mathbf{1 0 0 \%}$ & $\mathbf{1 2 \%}$ & $\mathbf{8 8 \%}$ \\
\hline
\end{tabular}

Data collection methods and tools

A number of data collection tools were adopted based on the objectives of the exercise. These tools are described as follows;

In-depth Interviews with Beneficiaries

Interviews with beneficiaries provided information about the services received, needs, challenges and sustainability efforts. 
Information from key informants helped to analyze the successes, needs and sustainability efforts of the services offered.

\section{Focus Groups Discussions}

FGDS with VHTs and parents about their perception on the services provided was vital in enriching the report.

\section{Data analysis and reporting}

A detailed analysis of quantitative and qualitative data from the beneficiary interviews was conducted using different statistical techniques. Findings were presented using age and gender socio-demographic categories. Qualitative data from key informant interviews and FGDs were analyzed using thematic analysis techniques and findings were used to strengthen the interpretation of the quantitative findings.

\section{Study Limitations}

While the assessment team did have access to individuals and other stakeholders to collect data, limitation to the assessment included: Some locations like Ruboni, Kamuli, Kakooga and Kiroro could not be accessed due to distance and Covid-19 related restrictions

\section{RESULTS}

\section{Demographics}

The findings presented in subsections 3.1.1 and 3.1.2 are results of the quantitative analysis of the evaluation data captured during the exercise. A questionnaire was administered to a total of 95 respondents of which $94 \%$ were female and $6 \%$ male. Nearly, all the respondents at $96 \%$ were between the ages of $20-30$ years, $85 \%$ of respondents were head of household. Nearly, all the respondents at $97 \%$ had 2 or more children living in their houses. In-terms of location, $60 \%$ of the respondents were from Kireka, $25 \%$ from Nakulabye and $15 \%$ Namuwongo.

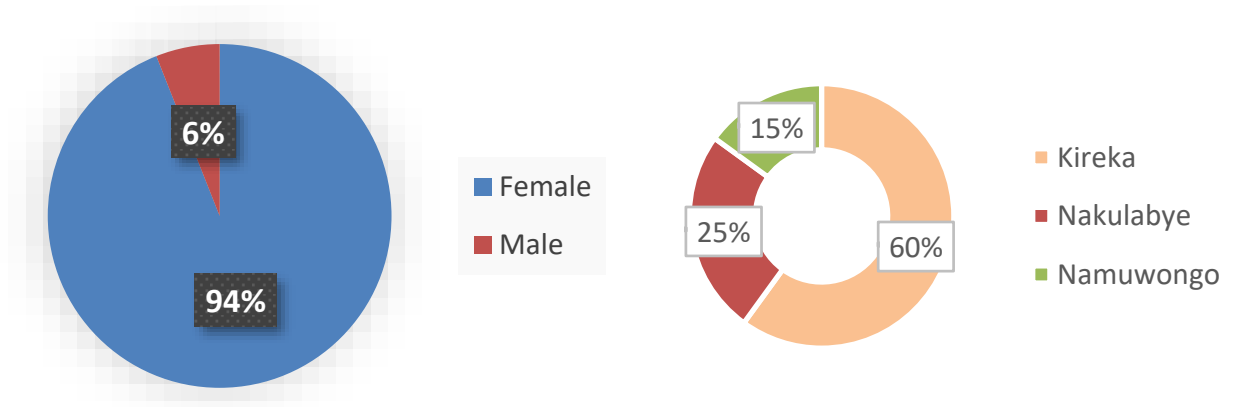




\section{Key Findings}

The key findings are detailed in three categories of beneficiaries,KIIs and FDG participants as below:

\section{Key Findings - Beneficiaries}

$47 \%$ of the respondents said they were chosen because they were vulnerable,32\% were needy and $18 \%$ by the community leader. This shows that the project activities were geared towards particular target groups who were vulnerable (Women, Orphaned children,HIV+ mothers, Adolescent girls)In terms of relevance, we were able to assess theextent to which the projectintervention, objectives and design responded to beneficiaries needs. It was realized that $96 \%$ of the services were provided when the beneficiaries needed them.

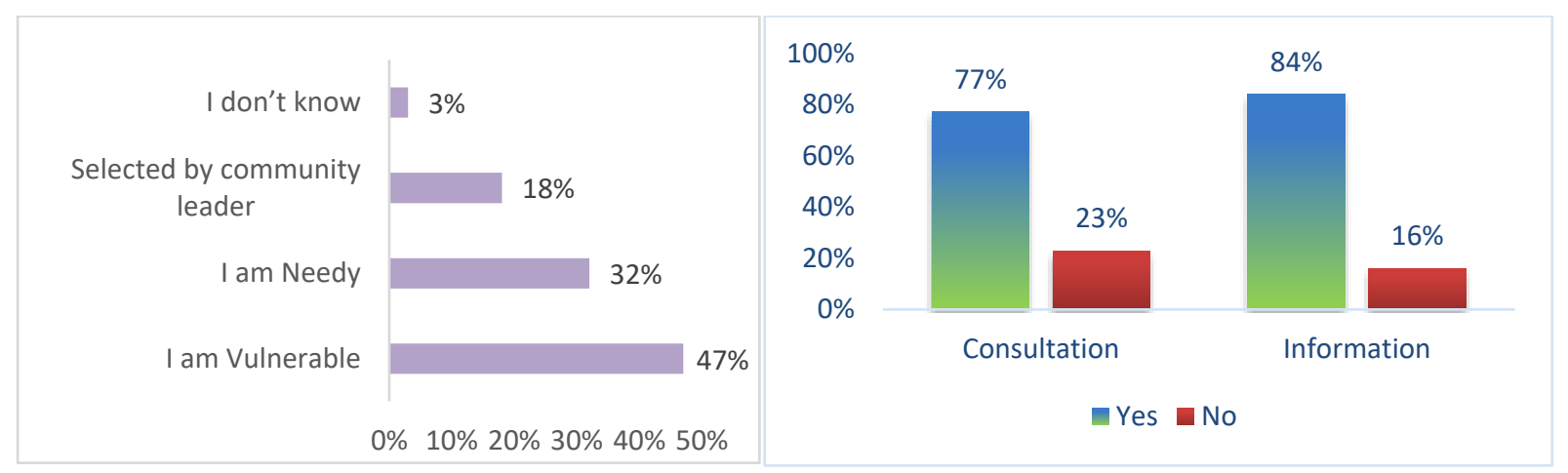

Figure3: Selection Criteria

Figure 4: Information and Consultation

Furthermore,77\% of the respondents said that they were consulted before implementation of activities while $23 \%$ were not. Additionally, $84 \%$ of the respondents said that they received information about the activities while $16 \%$ did not.

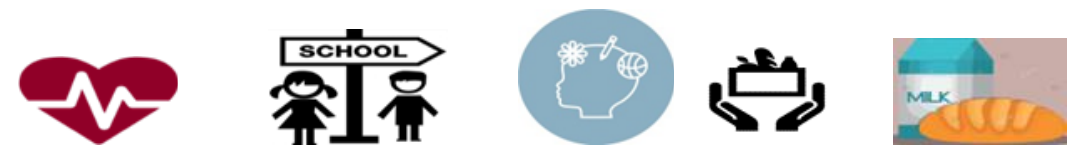

Health 10\% Education 16\% Psychosocial 27\% Relief items 4\% Nutrition 70\%

\section{Health-care}

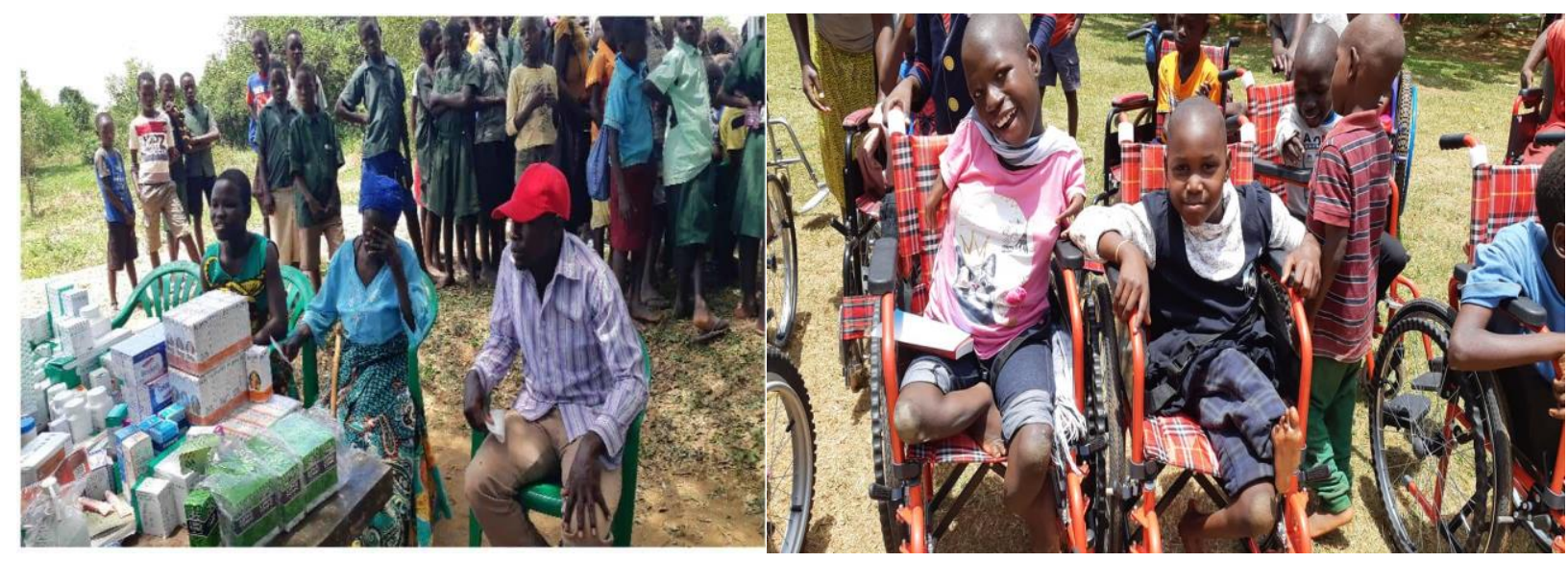

Photo I: Health camp in Masindi district

Photo II: Wheelchairs donated to KSPH

The main vision of AFL is to provide health intervention to deserving gifted children and families who are economically and socially deprived. AFL provided a range of health care related services aimed at improving the lives of children and their families through This publication is licensed under Creative Commons Attribution CC BY. 
International Journal of Scientific and Research Publications, Volume 11, Issue 2, February 2021 ISSN 2250-3153

health camps, and community outreaches. The list of activities conducted under the health camps include general treatment and consultation, HIV testing and referrals, deworming, children'sfeeding,counseling services,dental and eye clinic,family planning,cancer screening,STI screening and treatment,Hepatitis testing,antenatal care and support, health talk, safe male circumcision,pharmacy and dispensing,general laboratory services and blood donation.

On the services received by beneficiaries; $40 \%$ of the respondents said that they benefitted more from mental wellbeing services compared to $33 \%$ who benefited from hygiene management services. Dental and Eye services at $1 \%$ respectively were the least benefited. $82 \%$ of respondents participated in more than one health reated activity.97\% of the respondents said that the health camp sessions were helpful| while 3\% said they were not helpful.77\% of the respondents said that services helped them makehealthier wellbeing choices or improved health compared $23 \%$ who thought otherwise. The following ways were mentioned;

Table 3: Different ways health services impacted on beneficiaries.

\begin{tabular}{|ll|ll|ll|}
\hline$\bullet$ & Proper nutrition 6\% & $\bullet$ & Improved feeding habits5\% & $\bullet$ & Personal hygiene 4\%, \\
\hline$\bullet$ & Sanitation 4\% & $\bullet$ & Clean water.7\% & $\bullet$ & Health management9\% \\
\hline$\bullet$ & Disease prevention7\% & $\bullet$ & Health knowledge5\% & $\bullet$ & Balanced diet11\% \\
\hline$\bullet$ & Family planning10\% & $\bullet$ & Disease control \& treatment15\% & $\bullet$ & Health services $\mathbf{1 7 \%}$ \\
\hline$\bullet$ & Medical support8\% & $\bullet$ & Breastfeeding 12\% & $\bullet$ & Family health15\% \\
\hline
\end{tabular}

$35 \%$ of the respondents said that the health center was more than $2 \mathrm{kms}$ from their homes compared to $14 \%$ who said it was less than $500 \mathrm{~m} .88 \%$ of the respondents said that health services offered were very near $(88 \%)$ in terms of distance compared to $22 \%$ were said they were very far. This shows that services were brought nearer to the people and demand for more mobile clinics or nearby health facility

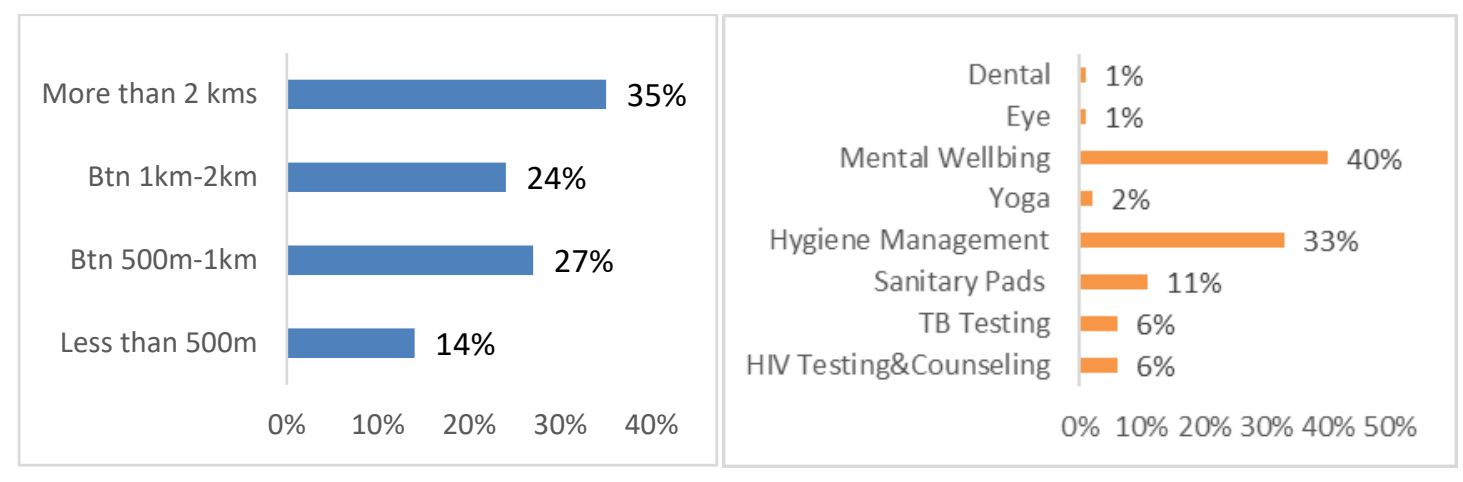

Figure5: Health services offered Figure 6: Distance to health center

In terms of relevance of activities, $58 \%$ of the respondents felt that the activities provided by Apar were helpful while $42 \%$ thought otherwise. Of the $42 \%$ who thought otherwise,they gave the following reasons;

- The quantity provided was not enough.

- The services only occurred for a short time and sometimes only once.

- Not everyone in the community benefitted. 
- The number of people who benefitted were few

\section{Psychosocial Support}

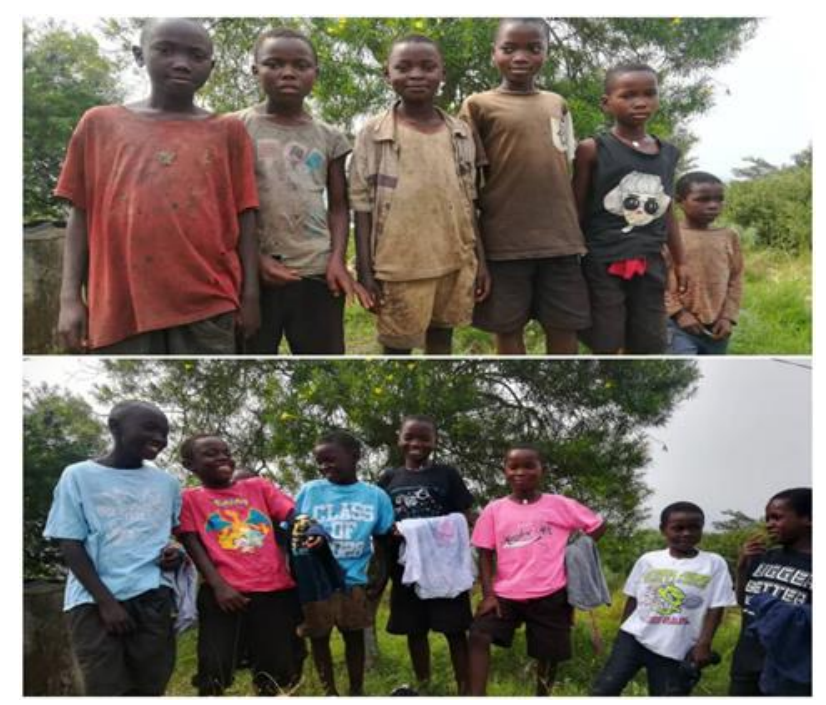

The psychosocial support provided by AFL aimed at reducing malnutrition and psychosocial deprivation which could have led to developmental delays and mental health problems in children. Interventions like nutritional support, clothes, toys, information on appropriate feeding practices, library services, and scholastic materials helped to promote positive child development and reduce the chance of mental health problems. One of the outcomes of the project was improved well-being of children's health and emotional behavior; therefore, the study sought out to assess to what extent this was met by exploring if the children's behavior, mental health and psychological needs were improved. These were categorized under three components of ability to cope, emotional and social wellbeing.

a. Emotional/personal well-being: From the analysis shared after the relief camp conducted in Kakooge and Ruboni area in Kasese district, it was realized that after two weeks of relief items distributions like clothes, toys, footwear, scholastic materials etc. that children exhibited positive feelings by looking happy and smiley, proud, more relaxed and hospitable, The donation of new clothes and shoes influenced the children's self-esteem in that they became more confidence in their own worth and abilities.

b. Social/interpersonal well-being: It was also observed that there was an improvement in social life of the children. The provision of food (lunch, porridge and milk), library services, games, Christmas programs etc. for children in Acholi quarters, Nakulaybe and Mpondwe increased relationships with peers and family as well as enabled a sense of belonging to a community and satisfaction with community environment. This physical and psychological caregiving provided by AFL encouraged positive social interaction by children who felt more energetic and became physically active and playful with friends and family.

c. Ability to cope: The beneficiaries realized that there was an improvement in their children's ability to cope after the provision of relief items and nutritional services. The children's personal skills were showed improvement in self-awareness, communication and increased interests to get involved in physical activities. The children's social skills and pro-social behavior were also improved. The child's behavior towards others was improved and the school environment felt safe for most of them. They started to enjoy school and its activities hence increasing on learning, for instance, nearly $90 \%$ of the 265 children who received clothes, books, shoes etc reported an increased interest in attending class regularly after 2 weeks of distribution in kakooge primary school.

\section{Education}




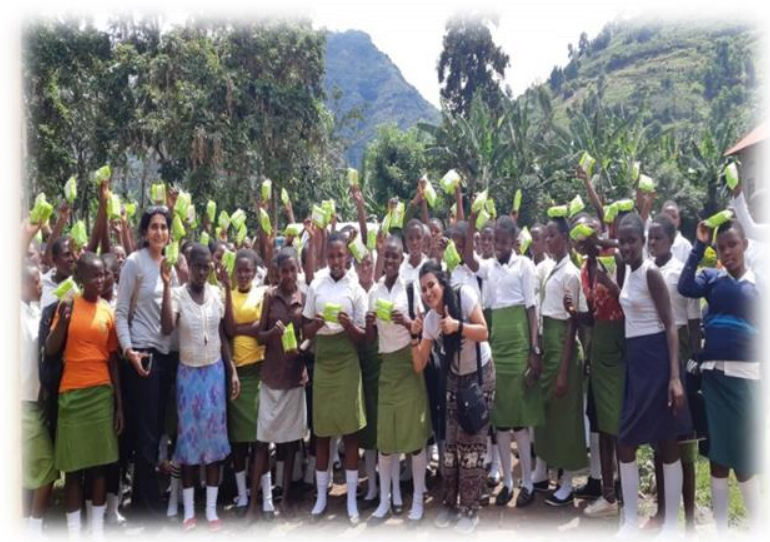

Photo V: Sanitary pads provision in Kasese district

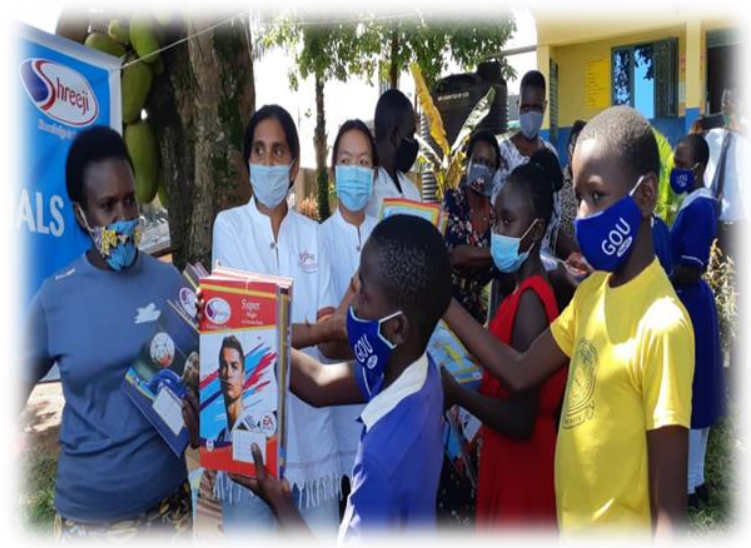

Photo Vi: Scholastic materials distribution at Busega

$76 \%$ of the respondents said that their children benefitted from education efforts provided by Apar foundation while $24 \%$ said otherwise. Provision of scholastic materials, sanitary pads, Reproductive health talks, library services, Lunch, breakfast and lessons were mentioned as services provided.

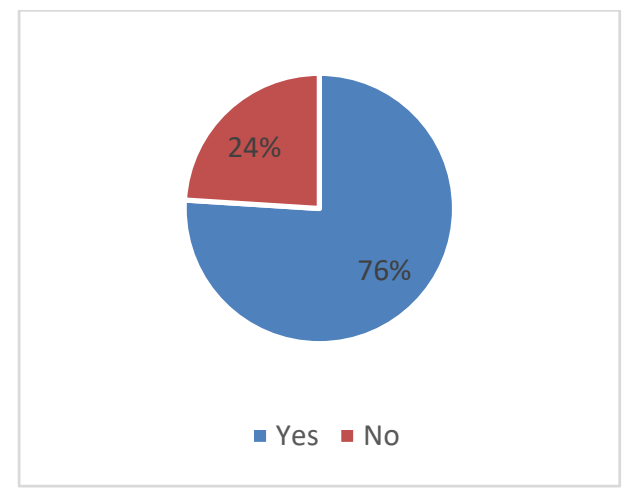

Figure 7: Education benefits

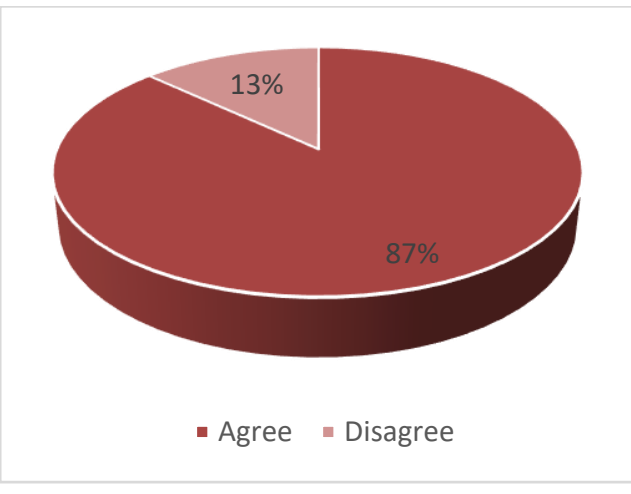

Figure 8: Learning sessions

$87 \%$ of the respondents felt that the learning sessions improved their child's learning needs while $13 \%$ thought otherwise.

\section{Nutrition}




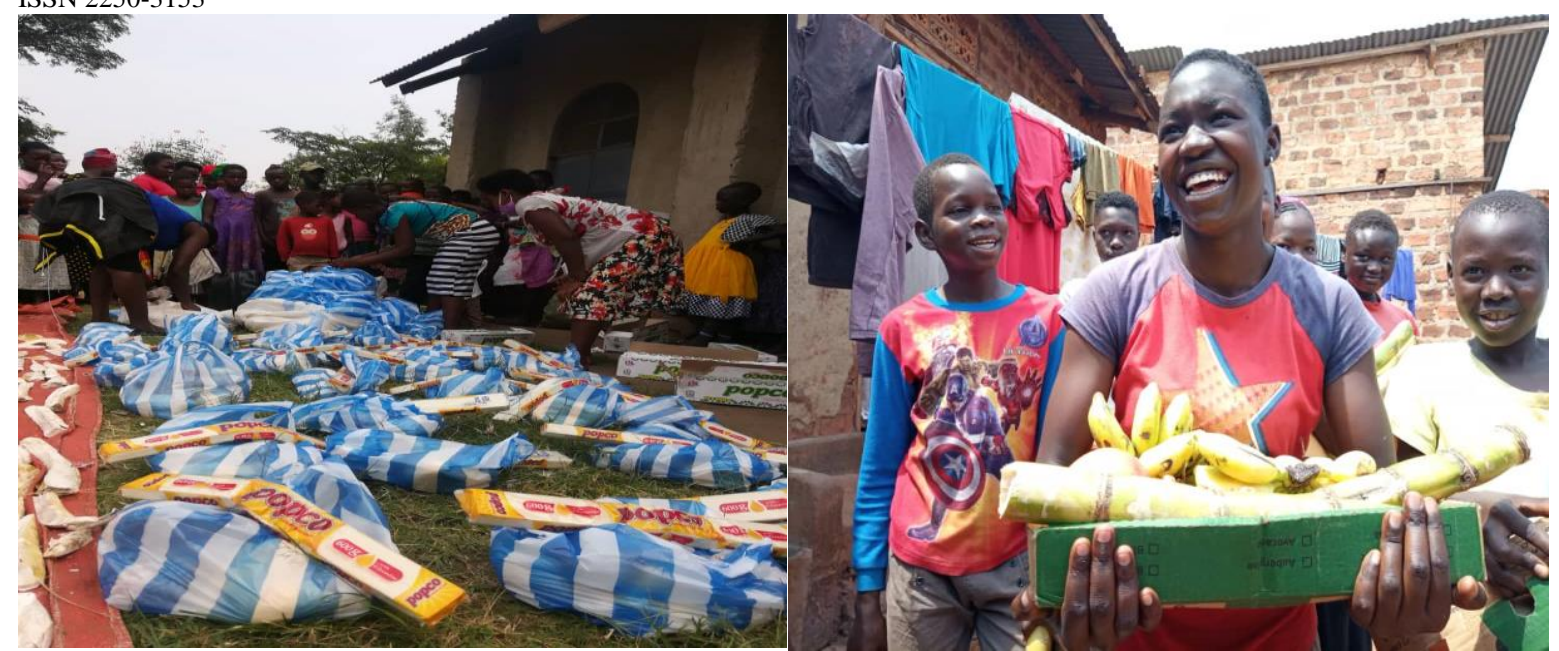

\section{Photo Vii: Food Support during Covid-19 in Mpondwe Photo Viii: Weekly nutrition program in Kireka.}

$92 \%$ of the respondents said that the nutrition services were helpful to them and their children while $8 \%$ said it was not helpful. They mentioned reduction in malnutrition, hunger averted, immunity boosted and reduction in diseases as ways that the nutrition was helpful. The beneficiaries received bread, porridge, milk, sugar, biscuit, soda, posho, rice and beans.

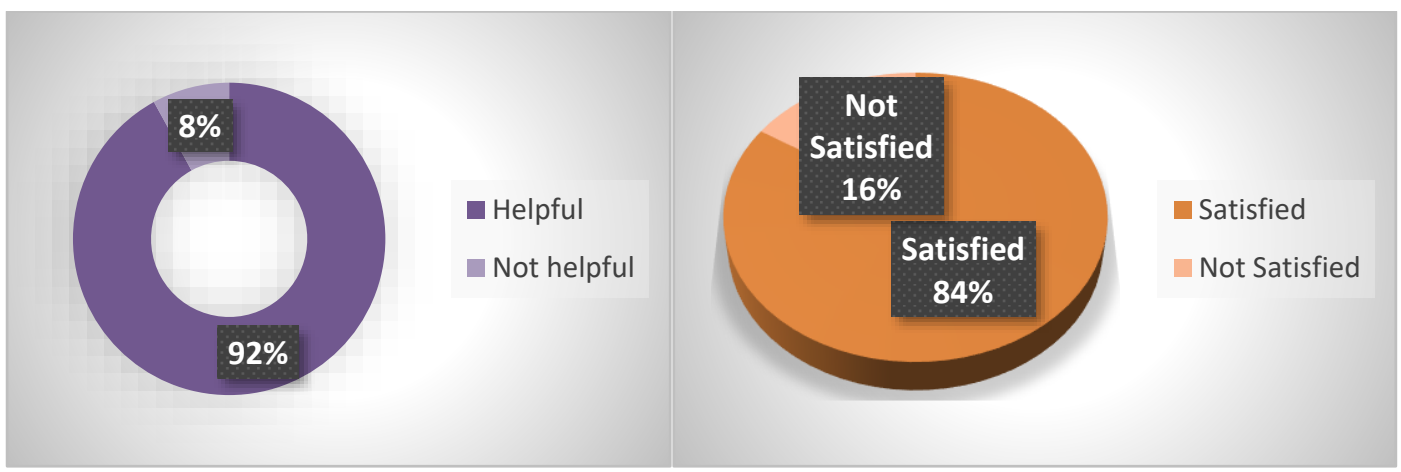

Figure 8: Rating of nutrition services

Figure 9: Satisfaction levels of services

$84 \%$ of the respondents were satisfied with services provided by Apar while $16 \%$ were not satisfied. Of those not satisfied they that the quantity was not enough for family.

\begin{tabular}{lll}
\hline Sector & Details & $\%$ \\
\hline Education & School fees, scholastic materials. Classrooms & $22 \%$ \\
Health & Health center, MHM kits and Sensitization & $32 \%$ \\
Nutrition & Rice, Soya & $18 \%$ \\
Livelihoods & IGAs, Business loans. & $28 \%$ \\
\hline
\end{tabular}


Impact: The responses helped to assess significant positive or negative, intended or unintended, higher level effects as below;

Nutritional support boosted the immunity of mothers and improved nutrition of children. Malnutrition and deficiency of minerals and vitamins affected most of the children but due to the supply $n$ provision of milk products and nutritious foods like soya, beans. they have a balanced diet and look healthy on top of averting hunger. Safe maternity care reduced on the risks of maternity death through provision of soap and milk powder.11 expecting Mothers who received bathing soap and milk powder at Kiraro camp safely delivered in different health facilities $n$ they are in good condition and they reported that it was because of the soap that they managed to have good hygiene.

Transport costs and free services. Distribution of services at a free cost,some people fear coming to hospital but feel free to come for outreach cut on transport costs and time since the services is brought near to the community

Knowledge improvement and awareness.Improvement of knowledge about MHM and the myth surrounding it. Created awareness for good health good hygiene and sanitation. Sustainable agriculture we encouraged them to grow more vegetables and benefits of a balanced diet meal to especially the younger ones.

Health welfare. Improved health community welfare and promoted well-being due to our medical camp by providing access to safe and effective medicine in Ruboni area.Helped to reduce hunger in the slum communities and eradication of bare footed related diseases like worm infections, fungal disease by providing for them foot wears like slippers to the campers n community.

Education support. Not many organizations can be of help in this aspect than Apar foundation, some others consider different aspects like scholastic materials forgetting this fundamental principle of mobility and accessibility.

Behavioral change has been realized among the children who are fed and taken through the spiritual sessions every Sunday in Acholi quarters.

Improved mobility of children. Increasing the mobility of children that have movement and other mobility challenges, Increase selfconfidence since each individual has the sense of ownership of the wheel chair, it gave a picture that there are people that are there for children with disabilities, for example parents were so much appreciative since wheel chairs are costly and not all parents are able to afford one. The right to mobility is fully restored in our special needs children which help them develop independently towards maximum functional independence. lots of changes were registered like better postural control and reduced development of secondary complications that come as a result of bad wheel chairs and this increased productivity in the children's school participation.

Improved self-confidence of children.Also our children's abilities and talents are put into use without issues of self-confidence, thus contributing directly to the wellbeing of children with disabilities and on their behalf.

MHM services. Supplying of sanitary pads to school going girls both in secondary and primary schools i.e snow line high school and Ruboni primary school. Younger girls deep in the villages can't access menstrual materials this some don't have money to even maintain buying sanitary products so some use clothes and polythene bags.

Relief services. Apar foundation gave relief of food, clothing, medication, foot wear and sanitary pads to the women in the camp of the people who have been affected by the flood. Its reported by the local authorities that some miss school, don't socialize with other and even all advised to go for early marriages. 
Counseling services. Counseling of young girls on the effect of early marriage and early pregnancies.

Tremendous effect on the livelihood of the indigenous people through direct benefit from the incentives and basic health care services provided by Apar. There is a strong sense of belonging and transformation these communities get when a caring hand as such reaches out.

\section{Key Findings - Focus Group Discussions}

In order to understand the perceptions and interests of the project activities conducted by the beneficiaries and volunteers of the project, a FGD was conducted to allow the assessment team to discuss the relevance, effectiveness and sustainability of the activities. The key findings are presented; Impact

- The treatment has helped to heal clients and their children. Due to Covid-19, health outreaches stopped and this has impacted on our lives.

- The outreaches helped the community since they could not access services like immunization.

- They have been able to access services like deworming, eye and dental which you cannot get for free at the hospital.

\section{CONCLUSION AND RECOMMENDATIONS}

\section{Conclusions}

The findings of this study have clearly demonstrated that the activities implemented by APAR clearly met the evaluation criteria of relevance, effectiveness, efficiency, impact and sustainability. It found varying degrees of impact and relevance and also several areas of improvement for current and future programming as well as sustainability efforts for continuity. On relevance, although the activities were provided when most needed and were one-off in some cases like relief camps, the need to have more frequent visits especially health, relief camps and community/school outreaches was noted. The variety of services provided during community outreaches was appreciated but the quantity of items provided and time was of concern. Most of the beneficiaries received services from nutrition compared to health and education sectors. Despite the services provided showing immediate impact, there's need to measure the services provided when immediately implemented like relief items to determine the long term impacts. It is important to note that besides education, health and nutrition, there is interest in livelihoods activities from the beneficiaries.

\section{Recommendations}

On the basis of the findings above, suggestions and recommendations for Apar foundation further strengthen project implementation. The recommendations combined the views of the beneficiaries, KIIs and FGDs participants. They are summarized into four areas of activity implementation, future programming, future needs and services and project sustainability.

\section{Activity implementation.}

In order to strengthen implementation of the on-going activities, the following were suggested;

- Start with health and then provide medicine, that is, emphasizing more of prevention than treatment.

- There is need for a minimum service package (Mama kits) during distribution of items 
- There is need for motivation of volunteers in terms of allowance in order to improve on follow up activities.

- Transportation of equipment during outreach should be catered for.

- Increased use of local leaders for mobilization of clients and beneficiaries.

- Besides bread/milk there's need for cereals like rice and beans.

- Expand the project activities to other areas outside Kampala.

- There is a request to conduct a TOT training for VHTs by Apar or a consultant in order to effectively utilize their services in the community.

\section{Future program improvement.}

- There is need for continued cooperation among community members and Local leaders and also establishment of an office for Apar for easy coordination.

- Youth programming in schools should also be considered just like adolescent girls.

- When providing assistive devices always use as much technical guidance as possible just like sometimes people donate equipment that is not relevant to individuals like oversized wheel chairs that end up causing secondary complications to the children.

- Increase the frequency of field days for community outreachand health camps to reach more people. Routine scheduled visits would be ideal because once in a while visits may not have lasting effect on total change if one wants to see lasting transformation.

- Invest in repairs and maintenance workshops to do repairs as well as orienting parents on how to take care of the devices provided.

\section{Sustainability.}

- Funding: Funding pool for sustainability grants more lobbying of funds from donors that are in line with support of children with disabilities. In terms of sustenance probably widen the advocacy bit and seek more support from potential donors.Need to increase resource mobilization strategies as well follow up activities.

- Continued Awareness: Educate mothers on nutrition, family planning, health information for the community on how to prevent diseases.

- Partnerships: Consider partnering and collaborating with KCCA health centers and other stakeholders to improve on community health being.

- Formation of Groups: Formation of women empowerment groups for single mothers \& HIV+ mothers to support them with income generating activities e.g. training in soap making, charcoal burning, mushroom growing.

\section{Needs \& Services.}

- Expansion of services to other rural and slum areas within and outside Kampala.

- Need to work together with VHTs and clients for follow up in their particular areas

- Need to continue sensitization sessions like teaching new born mothers

- Provide school fees and scholastic materials to children of clients.

- $\quad$ Provision safe and affordable drinking water and sanitation services, for instance, inKakooga. 
- $\quad$ Provision of business loans to clients to start up small businesses and income generating activities.

\section{REFERENCES}

FAO. (2014). State of Food Insecurity in the World 2013: The Multiple Dimensions of Food Security. FAO

Hakim S, Motlagh DA, Eshraghian M. Connection between food insecurity and some household socioeconomic factors and Body Mass Index (BMI) among the women in Dezful city. Journal of Hygienic Department and Research Institute. 2010;8(2):5566.

Hamilton, W. L., Cook, J. T., Thompson, W. W., \& Buron, L. F. (1997). Household food security in the United States in 1995: Summary report of the Food Security Measurement Project. Abt Associates.

Najibi, N., Dorosty-Motlagh, A. R., Sadrzadeh Yeganeh, H., \& Eshraghian, M. R. (2016). Relationship between Food Insecurity and Some Socioeconomic Factors and Type 2 Diabetes among newly diagnosed patients. Rahavard Salamat Journal, 1(2), 37-52

Oldewage-Theron, W. H., Dicks, E. G., \& Napier, C. E. (2006). Poverty, household food insecurity and nutrition: coping strategies in an informal settlement in the Vaal Triangle, South Africa. Public health, 120(9), 795-804.

Ostadrahimi, A., Mahboob, S. A., Dastgiri, S., \& dadgar, L. (2006). Prevalence and intensity of food insecurity (hunger and hidden hunger aspects) in AsadAbadi region of Tabriz.Yafteh, 8(1), 75-81.

Sharif, Z. M., \& Ang, M. (2001). Assessment of food insecurity among low income households in Kuala Lumpur using the Radimer/Cornell food insecurity instrument-a validation study. Malaysian Journal of Nutrition, 7(1 \& 2), 15-32.

Tabatabai, G. M., Omidwar, N., \& Alihoseini, J. (2011). Socioeconomic factors of food insecurity strength among the vulnerable population in district 20 of Tehran. Journal of Social Sciences, 52, 69-94. 